
\title{
25 Research Square \\ Genomic insights and probiotic characteristics of Bifidobacterium gallinarum CACC 514 isolated from canine
}

\section{Min Young Jung}

Center for Industialization of Agricultural and Livestock Microorganisms

\section{Yangseon Kim ( $\nabla$ yangseon@cialm.or.kr)}

Center for Industrialization of Agricultural and Livestock Microorganisms

Jung-Ae Kim

Center for Industrialization of Agricultural and Livestock Microorganisms

Dae-Hyuk Kim

Chonbuk National University

Research article

Keywords: Bifidobacterium gallinarum, gut microbe, probiotics, genome analysis, canine, feces.

Posted Date: December 2nd, 2019

DOI: https://doi.org/10.21203/rs.2.17977/v1

License: (c) (i) This work is licensed under a Creative Commons Attribution 4.0 International License.

Read Full License 


\section{Abstract}

Background: The genus Bifidobacterium includes common healthy gut microbes in mammals and is widely acknowledged as a probiotics with health-promoting properties.

Results: Bifidobacterium gallinarum CACC 514 was isolated from canine feces and its potential probiotic properties were characterized by comparative and functional genome analyses. The complete genome of strain CACC 514 was found to be $2.4 \mathrm{Mb}$, with a G + C content of $63.9 \mathrm{~mol} \%$. The strain possessed factors beneficial to mammalian health based on the presence of genes related to mucosal surface adhesion proteins, stress-related genes, and extracellular polysaccharide genes. A comparative genome analysis with other Bifidobacterium species revealed the unique characteristics of this species. These functional genomics have been confirmed for its superiority by probiotic properties, acid and bile tolerance, and adhesion to mucus.

Conclusions: The genome analysis and in vitro probiotics characteristics revealed its superiority in the intestine. These results add to our comprehensive understanding of $\mathrm{B}$. gallinarum and suggest that this strain has potential application in mammalian probiotics. Keywords: Bifidobacterium gallinarum, gut microbe, probiotics, genome analysis, canine, feces.

\section{Background}

Bifidobacteria were first isolated from the feces of a breastfed infant and were characterized as grampositive, non-motile, non-sporulating, anaerobic bacteria [1]. Bifidobacteria have been mostly isolated from the gastrointestinal tract of various mammals and birds, and more recently from food $[2,3]$. The genus Bifidobacterium belongs to the lactic acid bacteria (LAB) group, which currently comprises over 70 species described in the List of Prokaryotic Names with Standing in Nomenclature (LPSN, 2019).

Bifidobacteria form a significant proportion of the gut microbiota in animals and humans. Bifidobacteria are used as probiotics, and exert various health beneficial properties, such as antimicrobial activity against pathogenic bacteria, reduction of cancer, and prevention or treatment of inflammatory bowel disease (IBD) and diseases related to IBD including Crohn's disease (CD) and ulcerative colitis (UC) [4-7].

Probiotics are defined as 'live microorganisms which when administered in adequate amounts confer a health benefit on the host' retaining the previous definitions by Food and Agriculture Organization of the United Nations/World Health Organization (FAO/WHO, 2002)[8]. To benefit health, probiotic organisms require to have therapeutic effects, including gastric acid and bile compounds stability, adherence to the intestinal surface, and colonization to the intestinal tract [9]. Probiotics lactic acid bacteria were associated with intestinal barrier function by their metabolic products, such as short-chain fatty acids [10]. In particular, there has been a continuing report on the strong association between Bifidobacterium numbers and enhanced integrity and invasiveness of the intestinal epithelial cell barrier [11], and thus, enteric adhesion studies for this strain are important. 
The genomes of several probiotic Bifidobacterium strains including B. longum subsp. infantis, B. bifidum, and $B$. animalis subsp. lactis have been sequenced and analyzed in efforts to identify the genes and metabolic pathways related to their health-promoting traits [12-14]. However, considering the importance of biotechnology, the number of strains sequenced completely so far is still small and is largely limited to phylogenetic studies due to sampling bias for the Bifidobacterium species mentioned above [15]. The recognized taxa within the genus Bifidobacterium are divided into six main phylogenetic groups namely, B. asteroides, B. adolescentis, B. longum, B. pullorum, B. pseudolongum, and B. boum [16]. The genome of $B$. pullorum group species is also not completely analyzed.

In the present study, we isolated the B. gallinarum species (strain CACC 514) within the B. pullorum group from canine feces, and to the best of our knowledge, we identified its first complete genome sequences. The basic requirements of probiotic applications include resistance to gastrointestinal (GI) stress, the ability to colonize the gastrointestinal tract and to be metabolically active in the gastrointestinal tract [17]. The complete sequences of the CACC 514 genome were annotated and compared with the genomes of other Bifidobacterium strains to determine the basis of its potential and unique probiotic traits.

Furthermore, in vitro experiments for survival against gastric intestinal tract confirmed the positive effects as probiotics.

\section{Results And Discussion}

General genome features of Bifidobacterium gallinarum CACC 514

The complete genome of $B$. gallinarum CACC 514 contained a single circular chromosome of 2,414,462 bp with a GC content of $63.9 \%$ and one plasmid $(8,720 \mathrm{bp}$ ) with an average GC content of $64.2 \%$ (Table 1 and Fig. $1 \mathrm{~A}$ ). In total, 1,957 protein-coding sequences (CDSs) were identified. The chromosome contained 9 rRNAs, 57 tRNAs, 3 other ncRNAs, and 58 pseudogenes. The $\mathrm{G}+\mathrm{C}$ contents belong to genus Bifidobacterium (55-67\%) were similar to the values $64.2 \%$ of $B$. gallinarum DSM $20670^{\top}$ with $2.1 \mathrm{Mb}$ genome size, 5 rRNAs and 53 tRNAs $[15,18,19]$.

\section{Functional classification}

Each CDS in the annotated genome was grouped into the RAST subsystem category based on the predicted functional role (Additional File 1). Among the 2,102 CDSs, only 774 CDSs could be categorized into RAST subsystems, representing $36.8 \%$ of the total CDSs. Among the 2,102 categorized CDSs, the majority were classified into subsystems of protein metabolism (172 CDSs, 22.2\%), amino acids and derivatives (128 CDSs, 16.5\%), carbohydrates (117 CDSs, 15.1\%), and DNA metabolism (64 CDSs, $82.7 \%$ ). The remaining portion (63.2\%) could not be classified into any subsystem categories. Furthermore, 1,720 CDSs were specifically classified to a cluster of 19 COG-based functional categories (Fig. 1B). Most genes were classified into functional categories for carbohydrate transport and metabolism (199 genes), replication, recombination, and repair (163 genes), translation, ribosomal structure, and biogenesis (135 genes), amino acid transport and metabolism (128 genes), and transcription (112 genes). 
The PHAGER search tool identified 1 intact prophage and 2 incomplete phages in this genome (Additional file 2). One prophage region resembled Microb_Min1_NC_009603 (42.7 kb, region 1) with a GC content of $62.3 \%$. Bacteriophages are the most abundant biological entities and are known to impact genomic evolution and the adaptive capabilities of their bacterial hosts [20]. Bifidoprophages are present in a small number in multiple bifidobacterial species, indicating their relatedness to phages infecting other Actinobacteria, Firmicutes, as well as gram-negative bacteria [21, 22]. In addition, integrases are useful indicators of prophage diversity in bacterial genomes [23]. Prophage region 1 (804,476 - 847,197 bp) contained $58 \mathrm{CDSs}$, with a complete prophage integrase gene (Additional file 3). Consistent with the findings reported for bifidoprophages [22], the most conserved modules of the B. gallinarum CACC 514 were DNA packaging (encoding terminase, portal, and capsid proteins), lysogeny (encoding integrase gene), and tail morphogenesis module (encoding the tape measure protein).

CRISPR

The B. gallinarum CACC 514 genome contained 9 CRISPR loci (CRISPR 1 to 9), including 2 confirmed CRISPRs ( 3 and 4), and 7 questionable CRISPRs (1, 2, and 5-9) (Additional file 4). The strain CACC 514 was identified as a Type II-A system. Bifidobacterium species have unusually large and diverse CRISPRCas systems that constitute an adaptive immune system for antiviral defense in bacteria. CRISPR-Cas Type II immune systems (II-A, II-C) are fairly rare and occur in only $5 \%$ of bacteria, but they occur at a much higher frequency in the Bifidobacterium genus [24]. Characterization of Type II elementsmay provide opportunities to use the molecular genome-editing tool for the development of next-generation probiotic bacteria [25]. The B. gallinarum CACC 514 CRISPR-Cas system may also provide a platform for various potential biotechnological and ecological uses as probiotic bacteria.

\section{Stress-related proteins}

A number of stress-related proteins can regulate the adaptability of bacteria to the gastrointestinal tract [26]. CACC 514 possesses genes involved in stress-related pathways (Table 2). These stresses include temperature, $\mathrm{pH}$, and oxidative stress. CACC 514 carried various genes encoding heat shock proteins, groEL, groES, dnaJ, dnaK, grpE, $c / p B, c / p C$, and $c / p P$, and the small heat shock proteins (sHsps), hsp20 (Table 2). These genes are induced to respond upon exposure of bifidobacterial cultures to stressful condition, and overexpression of sHsps is known to increase tolerance to heat and osmotic stress in $B$. breve and $B$. longum NCC2705 [27]. CACC 514 encodes 2 genes for sodium-proton antiporter $(\mathrm{Na}+/ \mathrm{H}+)$, providing evidence of tolerance to low pH in the GI environment [23]. CACC 514 contains 9 genes for antioxidative proteins that are involved in minimizing the toxicity of active oxygen species (Table 2). $B$. longum has NADH oxidase, NADH peroxidase, and low superoxidase dismutase, whereas CACC 514 contains an NADH peroxidase and only 1 other predicted protein anaerobilin synthase (chuW) that is not found in Bifidobacterium species [28]. 
Potentially surface exposed (PSE) proteins and cell envelope-associated structures play crucial roles in establishing and maintaining interactions between the microbe and host epithelium [16]. All previously sequenced Bifidobacterium strains appear to encode an extracellular polysaccharide (EPS) or capsular polysaccharide. CACC 514 also encodes EPS (epsF, epsL, epsH, and epsJ),, and capsular polysaccharide (ABC-2.CPSE.A) (Table 2). These may contribute useful functions in the host such as adhesion, nutrient availability, pathogen inhibition, and immune system modulation in the bifidobacteria $[29,30]$.

\section{Phylogenetic analysis}

CACC 514 showed $99.2 \% 16$ S rRNA gene sequence similarity with $B$. gallinarum DSM $20670^{\top}$ and $B$. pullorum DSM $20433^{\top}$, and less than $97.0 \%$ similarity with $B$. saeculare DSM $6531^{\top}$ and $B$. longum subsp. infantis ATCC $15697^{\top}$, respectively (Additional file 5). The $96.5 \% \mathrm{ANI}(96.5 \%$ ) and $71.4 \%$ in silico DDH values revealed that the strain CACC 514 belongs to the same species as B. gallinarum DSM $20670^{\top}$ with higher values than the ANI and DDH cut-off values (Fig. 2) [31].

Core- and pan-genomes of CACC 514 and Bifidobacterium pullorum group strains

The complete CACC 514 genome was compared with the complete and incomplete genomes of 6 Bifidobacterium strains (Additional file 6). The genome of $B$. pullorum group strains could not be compared in this study, are there are no complete genome data reported in NCBI. These 7 genomes composed a pan-genome of 4,526 orthologous gene families and a core genome of 1,088 orthologous gene families (Additional file 7). In total, 271 genes in CACC 514 were unique (Additional file 8), including 236 hypothetical proteins. The 35 specific genes of CACC 514 included CRISPR-Cas 2, carbohydrate metabolism, phages, and cell wall and capsular polysaccharide-related genes. These outcome proteins will provide a higher ability for environmental change adaptation and adhesion to intestinal epithelial cells.

\section{Probiotics Properties}

Acid and Bile tolerances and intestinal adhesion

The acid and bile tolerance help in studying the survival of strain under low $\mathrm{pH}$ gastric juice condition and colonization of isolates in the small intestine [32]. The strain showed a high survival rate (\%) above $80 \%$ at low pH, and 0.3 and $1 \%$ bile salt concentration after $2 \mathrm{~h}$ exposure (Table 3 ). The CACC 514 with $82.80 \%$ adhesive ability to HT-29 cells was higher than the reference strain L. rhamnosus GG (Table 4).

\section{Antibiotic susceptibility}

The susceptibilities to the tested 12 antibiotics of CACC 514 was very susceptible to amoxcillin/clavulanic acid, ampicillin, clindamycin, impenem, metronidazole, tetracycline, vancomycin and erythromycin, which showed MICs $\leq 4 \mu \mathrm{g} / \mathrm{ml}$ (Table 5). These results was similar with the other probiotics Bifidobacterium species, $B$. adolescentis, $B$. animalis, B. bifidum, B. breve, and B. longum [33]. Bifidobacterium spp. had a high resistant to kanamycin above $500 \mu \mathrm{g} / \mathrm{ml}$ concentration [34], and the 
most have been reported as resistant to aminoglycoside antibiotic, because of the absence of cytochrome mediated drug transport system [35]. CACC 514 showed also the resistance to kanamycin ( $\geq$ $256 \mu \mathrm{g} / \mathrm{ml})$ and aminoglycoside gentamycin $(96 \mu \mathrm{g} / \mathrm{ml})$. These antibiotic susceptibilities were evaluated comparing MIC values to breakpoints suggested by European Food Safety Authority (EFSA) [36].

\section{Phenotypic (Fermentative) profiling}

The CACC 514 was utilized $D^{-G l u c o s e, ~ m a n n o s e, ~ m a n n i t o l, ~ l a c t o s e, ~ s u c r o s e, ~ m a l t o s e, ~ s a l i c i n, ~ x y l o s e, ~}$ arabinose, and raffinose was utilized. Esculin is hydrolyzed and nitrate is not reduced. The strain showed positive reactions for a-arabinosidase, esterase, leucine arylamidase, valine arylamidase, cystine arylamidase, alkaline phosphatase, naphthol-AS-BI-phosphohydrolase, a-galactosidase, $\beta$-galactosidase, a-glucosidase, and $\beta$-glucosidase.

\section{Conclusions}

Bifidobacterium is important in gut microbiome studies and has long been used as a probiotic to provide consistent beneficial health effects. Genomic analysis of $B$. gallinarum CACC 514 isolated from canine feces provided an overview of the potential mechanisms underlying the effect of the strain on host health. The specific genes of CACC 514 including CRISPR-Cas 2, carbohydrate metabolism, phages, and cell wall and capsular polysaccharide-related genes will provide higher adhesion to intestinal epithelial cells. In addition, in-vitro probiotic properties, low pH and bile resistance, and high adhesion to intestinal epithelial cells of CACC 514 validated genomic properties. Taken together, these studies demonstrate the potential as a probiotic of $B$. gallinarum strains within the B. pullorum group and substantially support the safe use of CACC 514 as a probiotic in the animal industry.

\section{Methods}

\section{Isolation of bacteria}

CACC 514 was isolated in Korea from dog feces (brown poodle, 4.8 years of age, male). Serial 10-fold dilutions of the fecal sample were prepared and cultivated on modified MRS (mMRS, de Man Rogosa and Sharpe with $0.05 \%$ cysteine- $\mathrm{HCl})$. Plated samples were incubated in an anaerobic atmosphere $(5 \%$ hydrogen and $5 \%$ carbon dioxide, and $90 \%$ nitrogen) for $48 \mathrm{~h}$ at $37^{\circ} \mathrm{C}$.

\section{DNA extraction and sequencing}

Genomic DNA was extracted using a DNeasy UltraClean microbial kit (Qiagen, Hilden, Germany) according to the manufacturer's instructions. The isolated DNA was sequenced using single molecular real-time (SMRT) sequencing technology with C4 chemistry and P6 DNA polymerase on the PacBio RS II system (Pacific Biosciences, Menlo Park, CA, United States) and Illumina HiSeq system (Illumina, San Diego, CA, United States) at Macrogen Inc. (Seoul, Republic of Korea). 


\section{Annotation}

De novo assembly of the single molecule real-time sequencing reads was performed using the hierarchical genome assembly process workflow (HGAP 3.0) in PacBio's SMRT portal with subreads from PacBio. After assembly, the paired-end reads from Illumina HiSeq 2500 were mapped to the assembled contigs to improve the accuracy of the genome sequences [37]. The sequences were annotated using the combined results of the automated NCBI Prokaryotic Genomes Annotation Pipeline (PGAP) and the RAST prokaryotic genome annotation server (http://rast.nmpdr.org/) [38]. The coding genes were predicted according to clusters of orthologous group (COG) using the WebMGA on-line tool [39]. Prophage insert regions were searched using the online phage search tool PHASTER (http://phaster.ca/), and clustered regularly interspaced short palindromic repeats (CRISPR) were predicted using the CRISPR web server (http://crispr.i2bc.paris-saclay.fr/) $[40,41]$.

\section{Phylogenetic analyses of Bifidobacterium strains}

Phylogenetic analysis was performed based on the 16S rRNA gene sequences. The 16S rRNA gene sequences of the CACC 514 and related species were aligned using the multiple sequence alignment program CLUSTAL W, and phylogenetic trees were then constructed using the neighbor-joining algorithm based on 1000 bootstrap replications in MEGA version 7 [42]. The ANI and in silico DDH values between Bifidobacterium strains were calculated using a standalone software (http://www.ezbiocloud.net/sw/oat) [43] and genome-to-genome distance calculator 2.1 (GGDC, http://ggdc.dsmz.de/distcalc2.php)[44], respectively.

\section{Pan-genome comparison}

Seven whole genome sequences from the $B$. pullorum group within the same clade in the phylogenetic tree of 16S rRNA gene and sequences of $B$. longum were selected for whole genome phylogenetic and comparative analysis. Bifidobacterium gallinarum DSM 20670 (GCA_000771505.1), B. pullorum DSM 20433 (GCA_000771405.1), B. saeculare DSM 6531 (GCA_000770965.1), and B. eulemuris DSM 100216 (GCA_002259685.1). The two B. longum subsp. longum JCM 1217 (GCA_000196555.1) and B. longum subsp. infantis ATCC 15697 (GCA_000020425.1) were used as the out-group in the phylogenetic analysis. The present sequenced genome, $B$. gallinarum CACC 514 was used for comparative analysis.

Pan-genome Orthologous Groups (POGs) were analyzed using BIOiPLUG comparative genomics software (ChunLab Inc., Seoul, Republic of Korea), and a heat map, UPGMA dendrogram, and Venn diagram were constructed based on these data.

\section{Quality assurance}

A single colony of the $B$. gallinarumstrain CACC 514 was repeatedly transferred to fresh mMRS medium to obtain pure cultures and the identity of the strain was verified through 16S rRNA gene sequencing. Genomic DNA strain CACC 514 was extracted using Qiagen DNeasy UltraClean microbial kit and then confirmed through a BLAST search of the 16S rRNA gene. 
Acidic $\mathrm{pH}$ resistance were assessed using MRS broth adjusted to $\mathrm{pH} 1.5$ and 2.5 with $6 \mathrm{~N} \mathrm{HCl}$ and incubated at $37^{\circ} \mathrm{C}$ for $30 \mathrm{~min}, 1 \mathrm{~h}$ and $2 \mathrm{~h}$. Bile tolerance was evaluated with MRS broth containing $0.3 \%$ $(\mathrm{w} / \mathrm{v})$ oxgall (BD Difco, USA) at $37^{\circ} \mathrm{C}$ for $2 \mathrm{~h}$. Viable number of bacteria were enumerated using MRS agar plate.

\section{Adhesion assay}

The human colon adenocarcinoma HT-29 cells were cultured in Dulbecco's Modified Eagle's Medium (DMEM, Gibco BRL, USA) supplemented with $10 \%$ fetal bovine serum (FBS), penicillin $(100 \mathrm{U} / \mathrm{ml}$ ) and streptomycin $(100 \mathrm{mg} / \mathrm{ml})$. Cells were incubated with DMEM medium lacking antibiotics before adhesion assay. LAB cultures suspended in DMEM medium without FBS and antibiotics were added into the wells containing HT-29 cell. The plates were incubated at $37^{\circ} \mathrm{C}$ for $2 \mathrm{~h}$ under $5 \% \mathrm{CO}_{2}$ and then the adherent bacteria were counted by plating the serial 10 -fold dilution of the suspensions using MRS agar plate. The L. rhamnosus GG (LGG, KCTC 5033) was used as reference strain. All probiotic activity were repeated three and results expressed as mean \pm standard deviation.

\section{Antibiotic susceptibility}

The MICs $(\mu \mathrm{g} / \mathrm{mL})$ of eleven antibiotics were determined using commercial E-test ${ }^{\circledR}$ (Epsilometer test, bioMerieux, France): amoxicillin/clavulanic acid, ampicillin, clindamycin, gentamicin, impenem, kanamycin, metronodazole, tetracycline, vancomycin, erythromycin, doxycycline and trimethoprim/sulfadiazin. The concentration on the strips was from 0.016 to $256 \mu \mathrm{g} / \mathrm{mL}$ with the exception of impenem and trimethoprim/sulfadiazin $(0.002-32 \mu \mathrm{g} / \mathrm{mL})$. Antibiotic susceptibility assay was performed according to methods described [45]. The MIC results was interpreted according to the criteria documented in the E-test technical guide.

\section{Phenotypic (Fermentative) profiling}

The sugar degradation and other enzyme properties of the CACC 514 strain were characterized by using an API 20A, API Rapid ID 32A, and API ZYM kit (Bio-Merieux, Marcy l'Etoile, France). The strain was grown until the logarithmic phase and then inoculated into API galleries according to the manufacturer's instructions.

\section{List Of Abbreviations}

CRISPR, clustered regularly interspaced short palindromic repeats; COG, clusters of orthologous group; $\mathrm{CD}$, Crohn's disease; EPS, extracellular polysaccharide; GI, gastrointestinal; IBD, inflammatory bowel disease; LAB, lactic acid bacteria; POGs, Pan-genome Orthologous Groups; PSE, potentially surface 
exposed; PGAP, Prokaryotic Genomes Annotation Pipeline; CDSs, protein-coding sequences; SMRT, single molecular real-time; UC, ulcerative colitis

\section{Declarations}

Ethics approval and consent to participate

Not applicable.

Consent for publication

Not applicable.

Availability of data and materials

The complete genome of strain CACC 514 determined in this study has been deposited with the NCBI GenBank database under accession numbers CP035464 (chromosome) and CP035465 (plasmid).

Competing interests

The authors declare that they have no competing interests.

Funding:

This study was supported by the Strategic Initiative for Microbiomes in Agriculture and Food funded by the Ministry of Agriculture, Food and Rural Affairs (918002-4).

Author Contributions

MYJ and YK wrote the manuscript. MYJ, JAK, and DHK performed DNA preparation, gene annotation, and comparative genome analysis. All authors read and approved the final manuscript.

Acknowledgments

Not applicable.

\section{References}

1.Tissier H: Le bacterium coli et la reaction chromophile d'Escherich. Crit Rev Soc Biol 1899, 51:943-945.

2.0'Callaghan A, Sinderen D: Bifidobacteria and their role as members of the human gut microbiota. Front Microbiol 2016, 7.925.

3.Laureys D, Cnockaert M, De Vuyst L, Vandamme P: Bifidobacterium aquikefiri sp. nov., isolated from water kefir. Int J Syst Evol Microbiol 2016, 66(3):1281-1286. 
4.Alard J, Peucelle V, Boutillier D, Breton J, Kuylle S, Pot B, Holowacz S, Grangette C: New probiotic strains for inflammatory bowel disease management identified by combining in vitro and in vivo approaches. Benef Microbes 2018, 9(2):317-331.

5.Fukuda S, Toh H, Hase K, Oshima K, Nakanishi Y, Ypshimura K, Tobe T, Clarke JM, Topping DL, Suzuki T et al: Bifidobacteria can protect from enteropathogenic infection through production of acetate. Nature 2011, 469:543-547.

6.Saez-Lara MJ, Gomez-Llorente C, Plaza-Diaz J, Gil A: The role of probiotic lactic acid bacteria and bifidobacteria in the prevention and treatment of inflammatory bowel disease and other related diseases: a systematic review of randomized human clinical trials. Biomed Res Int 2015, 2015:505878.

7.Ishikawa H, Akedo I, Umesaki Y, Tanaka R, Imaoka A, Otani T: Randomized controlled trial of the effect of bifidobacteria-fermented milk on ulcerative colitis. J Am Coll Nutr 2003, 22(1):56-63.

8.FAO/WHO: Guidelines for the evaluation of probiotics in food. Report of a Joint FAO/WHO Working Group. 2002 Available at: ftp://ftp.fao.org/es/esn/food/wgreport2.pdf.

9.Nazir Y, Hussain SA, Abdul Hamid A, Song Y: Probiotics and their potential preventive and therapeutic role for cancer, high serum cholesterol, and allergic and HIV diseases. BioMed Res Int 2018, 3428437.

10.Krumbeck JA, Rasmussen HE, Hutkins RW, Clarke J, Shawron K, Keshavarzian A, Walter J: Probiotic Bifidobacterium strains and galactooligosaccharides improve intestinal barrier function in obese adults but show no synergism when used together as synbiotics. Microbiome 2018, 6(1):121.

11.Cani PD, Neyrinck AM, Fava F, Knauf C, Burcelin RG, Tuohy KM, Gibson GR, Delzenne NM: Selective increases of bifidobacteria in gut microflora improve high-fat-diet-induced diabetes in mice through a mechanism associated with endotoxaemia. Diabetologia 2007, 50(11):2374-2383.

12.Charnchai P, Jantama SS, Jantama K: Genome analysis of food-processing stressful-resistant probiotic Bifidobacterium animalis subsp. lactis BF052, and its potential application in fermented soymilk. FEMS Microbiol Lett 2017, 364(17).

13.Andriantsoanirina V, Teolis AC, Xin LX, Butel MJ, Aires J: Bifidobacterium longum and Bifidobacterium breve isolates from preterm and full term neonates: comparison of cell surface properties. Anaerobe 2014, 28.212-215.

14.Linares DM, Gomez C, Renes E, Fresno JM, Tornadijo ME, Ross RP, Stanton C: Lactic Acid Bacteria and Bifidobacteria with Potential to Design Natural Biofunctional Health-Promoting Dairy Foods. Front Microbiol 2017, 8:846.

15.Sun Z, Zhang W, Guo C, Yang X, Liu W, Wu Y, Song Y, Kwok LY, Cui Y, Menghe B et al: Comparative genomic analysis of 45 type strains of the genus Bifidobacterium: a snapshot of its genetic diversity and evolution. PLoS One 2015, 10(2):e0117912. 
16.Turroni F, van Sinderen D, Ventura M: Genomics and ecological overview of the genus Bifidobacterium. Int J Food Microbiol 2011, 149(1):37-44.

17.Fukao M, Oshima K, Morita H, Toh H, Suda W, Kim SW, Suzuki S, Yakabe T, Hattori M, Yajima N: Genomic analysis by deep sequencing of the probiotic Lactobacillus brevis KB290 harboring nine plasmids reveals genomic stability. PLoS One 2013, 8(3):e60521.

18.Lee JH, O’Sullivan DJ: Genomi insights into Bifidobacteria. Microbiol Mol Biol Rev 2010, 74(3):378416.

19.Watabe J, Benno Y, Mitsuoka T: Bifidobacterium gallinarum sp. nov.: a new species isolated from the ceca of chickens. Int J Syst Bacteriol 1983, 43:185-193.

20.Canchaya C, Proux C, Fournous G, Bruttin A, Brussow H: Prophage genomics. Microbiol Mol Biol Rev 2003, 67(2):238-276.

21.Mavrich TN, Casey E, Oliveira J, Bottacini F, James K, Franz C, Lugli GA, Neve H, Ventura M, Hatfull GF et al: Characterization and induction of prophages in human gut-associated Bifidobacterium hosts. Sci Rep 2018, 8(1):12772.

22.Lugli GA, Milani C, Turroni F, Tremblay D, Ferrario C, Mancabelli L, Duranti S, Ward DV, Ossiprandi MC, Moineau $S$ et al: Prophages of the genus Bifidobacterium as modulating agents of the infant gut microbiota. Environ Microbiol 2016, 18(7):2196-2213.

23.Zhang W, Ji H, Zhang D, Liu H, Wang S, Wang J, Wang Y: Complete Genome Sequencing of Lactobacillus plantarum ZLP001, a Potential Probiotic That Enhances Intestinal Epithelial Barrier Function and Defense Against Pathogens in Pigs. Front Physiol 2018, 9:1689.

24.Briner AE, Lugli GA, Milani C, Duranti S, Turroni F, Gueimonde M, Margolles A, van Sinderen D, Ventura M, Barrangou R: Occurrence and Diversity of CRISPR-Cas Systems in the Genus Bifidobacterium. PLoS One 2015, 10(7):e0133661.

25.Hidalgo-Cantabrana C, Crawley AB, Sanchez B, Barrangou R: Characterization and Exploitation of CRISPR Loci in Bifidobacterium longum. Front Microbio/ 2017, 8:1851.

26.Kleerebezem M, Boekhorst J, van Kranenburg R, Molenaar D, Kuipers OP, Leer R, Tarchini R, Peters SA, Sandbrink HM, Fiers MW et al: Complete genome sequence of Lactobacillus plantarum WCFS1. Proc Natl Acad Sci U S A 2003, 100(4):1990-1995.

27.Khaskheli GB, Zuo F, Yu R, Chen S: Overexpression of Small Heat Shock Protein Enhances Heat-and Salt-Stress Tolerance of Bifidobacterium longum NCC2705. Curr Microbiol 2015, 71(1):8-15.

28.Schell MA, Karmirantzou M, Snel B, Vilanova D, Berger B, Pessi G, Zwahlen MC, Desiere F, Bork P, Delley $\mathrm{M}$ et al: The genome sequence of Bifidobacterium longum reflects its adaptation to the human 
gastrointestinal tract. Proc Natl Acad Sci U S A 2002, 99(22):14422-14427.

29.Castro-Bravo N, Wells JM, Margolles A, Ruas-Madiedo P: Interactions of Surface Exopolysaccharides From Bifidobacterium and Lactobacillus Within the Intestinal Environment. Front Microbiol 2018, 9.2426.

30.Salazar N, Gueimonde M, Hernandez-Barranco AM, Ruas-Madiedo P, de los Reyes-Gavilan CG: Exopolysaccharides produced by intestinal Bifidobacterium strains act as fermentable substrates for human intestinal bacteria. Appl Environ Microbiol 2008, 74(15):4737-4745.

31.Goris J, Konstantinidis KT, Klappenbach JA, Coenye T, Vandamme P, Tiedje JM: DNA-DNA hybridization values and their relationship to whole-genome sequence similarities. Int J Syst Evol Microbiol 2007, 57(Pt 1):81-91.

32.Somashekaraiah R, Shruthi B, Deepthi BV, Sreenivasa MY: Probiotic Properties of Lactic Acid Bacteria Isolated From Neera: A Naturally Fermenting Coconut Palm Nectar. Front Microbiol 2019, 10:1382.

33.Charteris WP, Kelly PM, Morelli L, Collins JK: Antibiotic susceptibility of potentially probiotic Bifidobacterium isolates from the human gastrointestinal tract. Lett App/ Microbiol 1998, 26(5):333-337.

34.D'Aimmo MR, Modesto M, Biavati B: Antibiotic resistance of lactic acid bacteria and Bifidobacterium spp. isolated from dairy and pharmaceutical products. Int J Food Microbiol 2007, 115(1):35-42.

35.Mayrhofer S, Mair C, Kneifel W, Domig KJ: Susceptibility of bifidobacteria of animal origin to selected antimicrobial agents. Chemother Res Pract 2011, 2011.989520.

36. Guidance on the assessment of bacterial susceptibility to antimicrobials of human and veterinary importance. EFSA Journal 2012, 10:2740.

37.Teng JLL, Yeung ML, Chan E, Jia L, Lin CH, Huang Y, Tse H, Wong SSY, Sham PC, Lau SKP et al: PacBio But Not Illumina Technology Can Achieve Fast, Accurate and Complete Closure of the High GC, Complex Burkholderia pseudomallei Two-Chromosome Genome. Front Microbiol 2017, 8:1448.

38.Aziz RK, Bartels D, Best AA, DeJongh M, Disz T, Edwards RA, Formsma K, Gerdes S, Glass EM, Kubal M et al: The RAST Server: rapid annotations using subsystems technology. BMC Genomics 2008, 9:75.

39.Wu S, Zhu Z, Fu L, Niu B, Li W: WebMGA: a customizable web server for fast metagenomic sequence analysis. BMC Genomics 2011, 12:444.

40.Grissa I, Vergnaud G, Pourcel C: CRISPRFinder: a web tool to identify clustered regularly interspaced short palindromic repeats. Nucleic Acids Res 2007, 35(Web Server issue):W52-57.

41.Arndt D, Grant JR, Marcu A, Sajed T, Pon A, Liang Y, Wishart DS: PHASTER: a better, faster version of the PHAST phage search tool. Nucleic Acids Res 2016, 44(W1):W16-21. 
42.Kumar S, Stecher G, Tamura K: MEGA7: Molecular Evolutionary Genetics Analysis Version 7.0 for Bigger Datasets. Mol Biol Evol 2016, 33(7):1870-1874.

43.Lee I, Ouk Kim Y, Park SC, Chun J: OrthoANI: An improved algorithm and software for calculating average nucleotide identity. Int J Syst Evol Microbiol 2016, 66(2):1100-1103.

44.Auch AF, Klenk HP, Goker M: Standard operating procedure for calculating genome-to-genome distances based on high-scoring segment pairs. Stand Genomic Sci 2010, 2(1):142-148.

45.Georgieva R, Yocheva L, Tserovska L, Zhelezova G, Stefanova N, Atanasova A, Danguleva A, Ivanova G, Karapetkov N, Rumyan N et al: Antimicrobial activity and antibiotic susceptibility of Lactobacillus and Bifidobacterium spp. intended for use as starter and probiotic cultures. Biotechnol Biotechnol Equip 2015, 29(1):84-91.

\section{Tables}

Table 1. Overview of the Bifidobacterium gallinarum CACC 514 genome

\begin{tabular}{lcc}
\hline Attribute & Chromosome & Plasmid \\
\hline Size $(\mathrm{Mb})$ & 2.41 & 0.01 \\
\hline GC\% & 63.9 & 64.2 \\
\hline Protein & 1,951 & 6 \\
\hline rRNA & 9 & - \\
\hline tRNA & 57 & - \\
\hline Other RNA & 3 & - \\
\hline Pseudogene & 58 & - \\
\hline Accession No. & CP035464 & CP035464 \\
\hline
\end{tabular}

Table 2. Genes related to stress adaptation and adhesion in B. gallinarum CACC 514 


\begin{tabular}{|c|c|c|c|c|c|}
\hline & CDS name & Other name(s) & Product & Length & Location \\
\hline \multirow[t]{14}{*}{ Temperature } & gene_00157 & HtpX & Protease HtpX like protein & 957 & $204082 . .205038$ \\
\hline & gene_00307 & $\mathrm{ClpB}$ & Chaperone protein $\mathrm{ClpB}$ & 2652 & $397922 . .400573$ \\
\hline & gene_00759 & ClgR & Transcriptional regulator ClgR & 513 & 959703..960215 \\
\hline & gene_00799 & clpP|CLPP & Endopeptidase Clp & 612 & 1016297..1016908 \\
\hline & gene_00800 & clpP|CLPP & Endopeptidase Clp & 702 & 1016928..1017629 \\
\hline & gene_00832 & & $\begin{array}{l}\text { Acid shock protein; small heat shock } \\
\text { protein (HSP20) family }\end{array}$ & 456 & 1050933..1051388 \\
\hline & gene_01069 & HrcA & $\begin{array}{l}\text { Heat-inducible transcription repressor } \\
\text { HrcA; grpE- dnaK-dnaJ and groELS } \\
\text { operons }\end{array}$ & 1098 & $1301525 . .1302622$ \\
\hline & gene_01070 & & Chaperone protein DnaJ & 1146 & 1302676..1303821 \\
\hline & gene_01501 & & $\begin{array}{l}\text { ATP-dependent Clp protease ATP-binding } \\
\text { subunit ClpA like protein CD } 4 \text { A, } \\
\text { chloroplastic }\end{array}$ & 2541 & 1713433..1715973 \\
\hline & gene_01834 & & $\begin{array}{l}10 \mathrm{kDa} \text { chaperonin; GroES chaperonin } \\
\text { family }\end{array}$ & 294 & $2095638 . .2095931$ \\
\hline & gene_02064 & HspR & Putative heat shock protein HspR & 573 & $2386201 . .2386773$ \\
\hline & gene_02065 & DnaJ & Chaperone protein DnaJ & 1008 & $2386940 . .2387947$ \\
\hline & gene_02066 & & Protein GrpE & 723 & $2388049 . .2388771$ \\
\hline & gene_02067 & & Chaperone protein dnaK1 & 1866 & $2388787 . .2390652$ \\
\hline \multirow[t]{2}{*}{$\mathrm{pH}$} & gene_00100 & & $\begin{array}{l}\text { Sodium, potassium, lithium and } \\
\text { rubidium/H(+) antiporter }\end{array}$ & 2076 & $130424 . .132499$ \\
\hline & gene_00805 & NhaA & $\mathrm{Na}(+) / \mathrm{H}(+)$ antiporter NhaA & 1314 & 1020818..1022131 \\
\hline \multirow[t]{10}{*}{ Oxidative stress } & gene_00032 & $\operatorname{trxB|TRR}$ & Thioredoxin-disulfide reductase & 1770 & $46079 . .47848$ \\
\hline & gene_00033 & PRDX2_4|ahpC & Peroxiredoxin & 564 & $47979 . .48542$ \\
\hline & gene_00064 & $\operatorname{trxB|TRR}$ & Thioredoxin-disulfide reductase & 933 & $81630 . .82562$ \\
\hline & gene_00211 & BCP|PRXQ|DOT5 & Peroxiredoxin & 489 & $274591 . .275079$ \\
\hline & gene_00346 & & uncharacterized protein & 957 & $446729 . .447685$ \\
\hline & gene_00423 & & Protein disulfide-isomerase & 360 & $557893 . .558252$ \\
\hline & gene_01016 & chuW & Anaerobilin synthase & 1260 & $1232597 . .1233856$ \\
\hline & gene_01422 & npr & NADH peroxidase & 1746 & 1613981..1615726 \\
\hline & gene_01489 & $\operatorname{trxB|TRR}$ & Thioredoxin-disulfide reductase & 255 & $1698312 . .1698566$ \\
\hline & gene_01664 & fadH & 2,4-dienoyl-CoA reductase (NADPH) & 2010 & $1913824 . .1915833$ \\
\hline \multirow{6}{*}{$\begin{array}{l}\text { Extracellular } \\
\text { polysaccharide } \\
\text { (EPS) }\end{array}$} & gene_00388 & epsF & Putative glycosyltransferase EpsF & 1098 & $506424 . .507521$ \\
\hline & gene_00389 & epsF & Putative glycosyltransferase EpsF & 1110 & $507505 . .508614$ \\
\hline & gene_00413 & epsL & Uncharacterized sugar transferase EpsL & 1626 & $541499 . .543124$ \\
\hline & gene_00385 & waaH|EpsH & Putative glycosyltransferase EpsH & 1059 & $502775 . .503833$ \\
\hline & gene_00390 & amsB|EpsJ & $\begin{array}{l}\text { Uncharacterized glycosyltransferase } \\
\text { EpsJ }\end{array}$ & 1002 & 509807..510808 \\
\hline & gene_01984 & waaV|EpsH & Putative glycosyltransferase EpsH & 1038 & $2277617 . .2278654$ \\
\hline $\begin{array}{l}\text { Capsular } \\
\text { polysaccharide }\end{array}$ & gene_00825 & ABC-2.CPSE.A & $\begin{array}{l}\text { Capsular-polysaccharide-transporting } \\
\text { ATPase }\end{array}$ & 744 & 1044643..1045386 \\
\hline
\end{tabular}

\section{Table 3. Acid and bile tolerance of B. gallinarum CACC 514}




\begin{tabular}{c|c|c|c}
\hline \multirow{2}{*}{} & \multicolumn{3}{|c}{ Viable cell count (Log CFU/ml) } \\
\cline { 2 - 4 } & Acid tolerance & \multicolumn{2}{|c}{ Bile tolerance } \\
\cline { 2 - 4 } & pH2.5 & $\mathbf{0 . 3 \%}$ oxgall & $\mathbf{1 \% ~ o x g a l l}$ \\
\hline 0h & $7.97 \pm 0.02$ & $7.97 \pm 0.02$ & $7.97 \pm 0.02$ \\
\hline 2h & $6.84 \pm 0.16$ & $7.17 \pm 0.01$ & $6.63 \pm 0.09$ \\
\hline Survival rate(\%) & 85.77 & 89.92 & 83.13 \\
& & & \\
\hline
\end{tabular}

Table 4. Intestinal adhesion activity of $B$. gallinarum CACC 514

\begin{tabular}{c|c|c}
\hline \multirow{2}{*}{} & \multicolumn{2}{|c}{ Viable cell count (Log CFU/ml) } \\
\cline { 2 - 3 } & CACC 514 & L. rhamnosus GG \\
\hline $0 \mathrm{~h}$ & $7.88 \pm 0.13$ & $7.63 \pm 0.23$ \\
\hline $\mathrm{h}$ & $6.52 \pm 0.07$ & $6.25 \pm 0.11$ \\
\hline Adherence (\%) & 82.8 & 81.93 \\
& & \\
\hline
\end{tabular}

Table 5. Antibiotic susceptibility of B. gallinarum CACC 514. Bacterial susceptibility to antibiotic was determined according to the cut-off values given by EFSA (2012). R, resistant; n.r, not recommended.

\begin{tabular}{l|c|c}
\hline \multirow{2}{*}{ Antibiotics } & \multicolumn{2}{|c}{ Minimal inhibition concentraion (MIC, $\mathbf{\mu g} / \mathbf{m L}$ ) } \\
\cline { 2 - 3 } & CACC 514 & EFSA cut-off \\
\hline Amoxcillin/Clavulanic acid (XL) & 0.125 & n.r \\
Ampicillin (AM) & 0.094 & 2 \\
Clindamycin (CM) & 0.016 & 1 \\
Gentamicin (GM) & 96 & 64 \\
Impenem (IP) & 0.5 & n.r \\
Kanamycin (KM) & $>256^{\mathrm{R}}$ & n.r \\
Metronidazole (MZH) & 4 & n.r \\
Tetracycline (TC) & 4 & 8 \\
Vancomycin (VA) & 1 & 2 \\
Erythromycin (EM) & 0.032 & 1 \\
Trim/Sulfa (TS) & 0.032 & n.r \\
Doxycycline(DC) & 4 & n.r \\
\hline
\end{tabular}




\section{Figures}

A

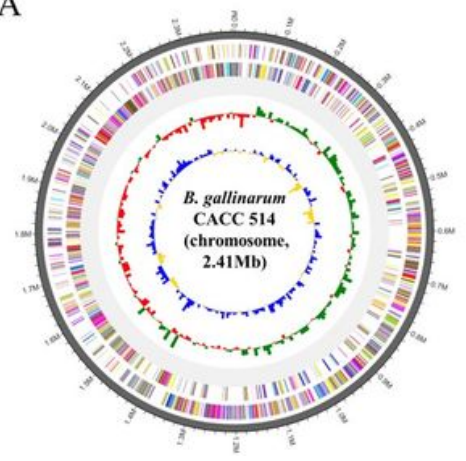

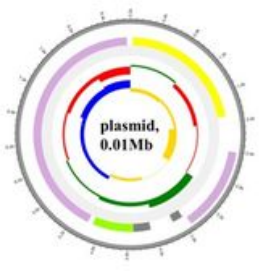

$\mathrm{B}$

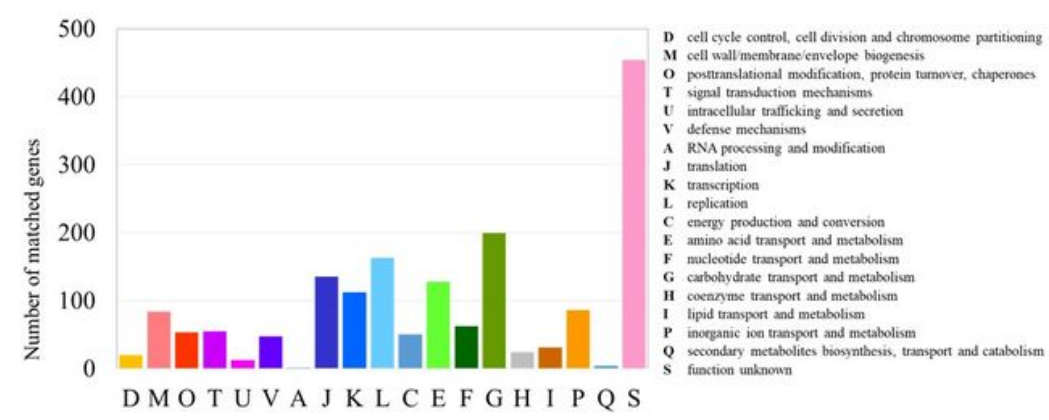

Figure 1

Genome features of Bifidobacterium gallinarum CACC 514. (A) Circular genome maps of Bifidobacterium gallinarum CACC 514 chromosome and plasmid. Circles from the outside to the center denote rRNA and tRNA genes, reverse strand CDS, forward strand CDS, GC skew, and GC content. (B) Genome number of COG categories.
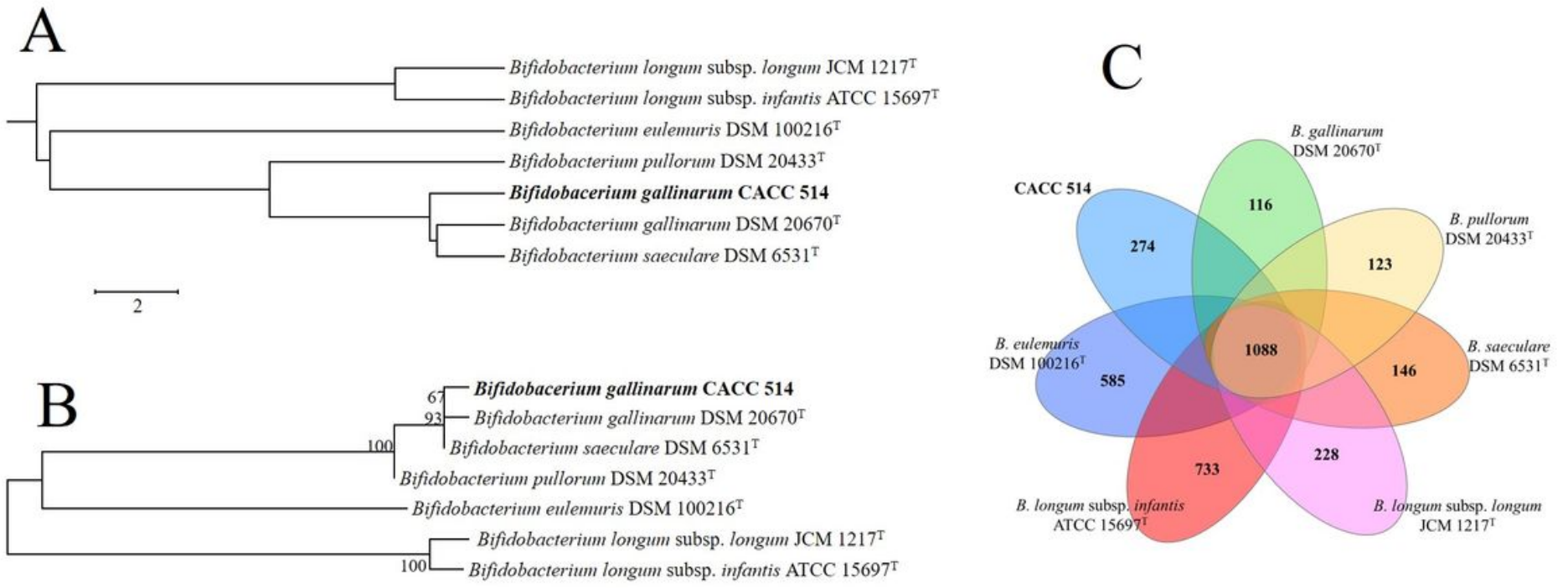

\section{Figure 2}

Phylogenetic tree based on average nucleotide identity (ANI, A) and in silico DNA-DNA hybridization (DDH, B) values showing pair-wise relatedness between 7 Bifidobacterium strains. (C) Venn diagram showing 
the number of orthologous gene groups of the core genome (the center part) and the unique genes of each genome among 7 Bifidobacterium strains.

\section{Supplementary Files}

This is a list of supplementary files associated with this preprint. Click to download.

- Additionalfile234678.xlsx

- additionalfiles.docx

- Additionalfile5..jpg

- Additionalfile1..jpg 